\title{
Entre relações desvendadas e afetos em disputa: a presença de Também Somos Irmãos (1949) no cinema brasileiro dos anos 1940-50
}

\author{
Pedro Vinicius Asterito Lapera
}

Resumo: Este artigo pretende analisar os modos pelos quais o filme Também Somos Irmãos (José Carlos Burle, 1949) apresentou seus personagens a partir das identidades étnico-raciais. Abordaremos também como os discursos sobre raça que circulavam socialmente à época foram apropriados na discussão proposta pela obra. Descrevemos resumidamente a ação do filme: dois irmãos negros criados em uma casa - cujo patriarca Requião era branco e racista - escolhem duas trajetórias contrapostas melodramaticamente. Enquanto Renato escolhe a carreira jurídica, Miro opta pela marginalidade como forma de contestação dos valores do "mundo dos brancos".

Palavras-chave: cinema; Burle; identidades étnico-raciais.

Abstract: Among unrevealed relations and affections in struggle: the presence of Também Somos Irmãos (1949) in Brazilian Cinema of the 1940-50 - This article intends to analyze the ways in which the movie Também Somos Irmãos (José Carlos Burle, 1949) have introduced its characters and their ethnic, racial identities. We also explore how the discourse about race, which was socially valid at that time, has been reappropriated in the discussion proposed by the movie. Briefly, we can describe the plot of the movie: two Afro-Brazilian brothers were raised by a racist stepfather and they chose different paths melodramatically opposed. While Renato chose a juridical career, Miro preferred marginality as a way of contestation of "white values".

Keywords: cinema; Burle; ethnic identities. 


\section{Introdução}

Dentre as muitas transformações advindas com a modernidade, as relações de afeto foram um lócus privilegiado para verificar de que formas aquelas se deram. A instabilidade do sujeito no mundo moderno ocasionou seu reposicionamento no mercado do afeto de acordo com padrões de classe, raça, gênero, idade e outros fatores classificatórios. Além disso, criou a necessidade de que novos valores pautassem essas relações e de que chaves de leitura, como o melodrama, fossem acionadas nesses arranjos (SINGER, 2001).

Em se tratando de retóricas raciais e étnicas, no caso brasileiro, foi paulatinamente disseminada a ideia de que a colonização portuguesa produzira uma cultura na qual os conflitos de ordem étnico-racial foram apaziguados. Tal leitura ocorreu a partir da publicação das obras de Gilberto Freyre e também de Sérgio Buarque de Holanda, nos anos 1930. Seguindo esta interpretação, em nossa modernidade, o peso do dado racial teria sido menos determinante no impedimento/frustração de relações afetivas.

Entretanto, no meio século anterior a isso, algumas teorias raciais importadas de pensadores europeus ao longo do séc. XIX ajudaram a conformar tanto um senso comum racista e que priorizava o ideal de branqueamento da população quanto políticas de Estado que favoreceram a imigração europeia (isto é, de população branca) nesse período.

Neste quadro, o filme Também Somos Irmãos (1949) - dirigido por José Carlos Burle e com roteiro de Alinor Azevedo - retoma a temática do preconceito racial para contestar algumas ideias sobre relações raciais então em voga e, particularmente, sobre o impacto do senso comum racista nas relações afetivas. Esse filme se insere em um vasto panorama de produções cinematográficas que, no pós-guerra, retrataram dramas sociais pela chave do melodrama, tais como A Luz é para todos (ELIA KAZAN, 1947) e Imitação da vida (DOUGLAS SIRK, 1959), ou mesmo Luz dos seus olhos (1947), também roteirizado por Alinor Azevedo e dirigido por José Carlos Burle.

Partimos da relevância da matriz melodramática na representação de dramas sociais para lançar a seguinte questão: de que modos certas ideias sobre relações raciais no Brasil são representadas em Também Somos Irmãos? Trabalhamos com a hipótese de que, em sua representação, o filme aciona algumas práticas discursivas em relação à raça de modo incidental, tais como: repulsa à miscigenação, ideal de branqueamento, preconceito e democracia racial.

Antes de retomarmos alguns pontos levantados pelo filme, precisamos fazer remissão à dissertação Argumento e roteiro: o escritor de cinema Alinor Azevedo, de Luis Alberto Rocha Melo (2006). Nela, o autor realiza uma extensa análise a respeito dos realizadores, da produção do filme e de sua recepção. Precisamos reconhecê-la como um importante ponto de partida para as reflexões a serem aqui empreendidas.

É necessário, ainda, destacar nosso foco na análise da obra, com pequenas considerações sobre sua recepção crítica, a partir de quatro eixos: a) a circulação espacial 
de brancos e negros na narrativa; b) as barreiras melodramáticas ao par inter-racial; c) os usos de uma linguagem racista; e d) a capacidade projetiva dos protagonistas negros.

\section{Também Somos Irmãos, um filme precursor?}

Resumidamente, poderíamos descrever a ação do filme como dois irmãos negros, criados em uma casa cujo patriarca Requião era branco e racista, que assumem duas trajetórias contrapostas melodramaticamente. Enquanto Renato (interpretado por Aguinaldo Camargo, ator do Teatro Experimental do Negro) estuda para obter o título de Bacharel em Direito, Miro (interpretado por Grande Othelo, ator já conhecido das produções da Atlântida e do Teatro de Revista) opta pela marginalidade, identificada nos crimes de pequeno porte empreendidos por ele ao longo do filme. Como catalisadores da ação, há Martha (Vera Nunes), filha adotiva branca de Requião e por quem Renato nutre um amor platônico, e Walter Mendes (Jorge Dória), um vigarista branco aliado de Miro, que seduz Martha para dar um golpe em Requião.

Melo (2006, p. 116-119) identificou uma tensão entre a proposta publicitária da Atlântida de tentar vender o filme como filiado ao neorrealismo italiano e a recepção crítica que ignorou essa leitura e ressaltou negativamente seu conteúdo melodramático. Em seguida, o autor recordou que, na hierarquia dos gêneros praticada à época, um filme ser rotulado como melodrama era considerado um minus, ao passo que ser ligado ao neorrealismo reforçava o capital simbólico da obra (BOURDIEU, 2005), uma vez que esse era um movimento cinematográfico que vinha então ganhando prestígio entre os críticos e apreciadores de cinema. ${ }^{1}$ Melo trouxe, ainda, esses dois regimes de representação à análise que elaborou de modo bem instigante sobre a obra. A nós, interessa principalmente como estes foram incorporados às construções sobre povo e raça presentes no drama de Também Somos Irmãos.

Inserindo-se numa perspectiva neorrealista de ambientar as ações fílmicas em locações ao ar livre que sejam consideradas a partir do universo das personagens (em vez de estúdios), o filme é iniciado dentro de uma favela com uma perseguição policial a Miro, cujo fim ocorre pelo despistar da polícia e pelo encontro com seu irmão Renato.

Mais à frente, Renato prepara-se em sua casa para seu baile de formatura e é ovacionado pelos seus vizinhos na favela. Nesta cena, a integração do povo é acionada dentro da perspectiva do ideal de democracia racial, uma vez que brancos e negros são mostrados no mesmo espaço, celebrando a vitória do protagonista.

Para o baile, Renato convidou Martha, que não pôde comparecer por um motivo alheio a sua vontade. Nesta sequência, há a construção de um POV² no qual Renato é

1 Além disso, segundo Melo (2006, p. 116-119), a própria noção de realismo comporta valores como seriedade e contenção, tais como foram sublinhados nas poucas críticas positivas ao filme (Pedro Lima, em O fornal e Fred Lee, n'O Globo).

2 Do inglês point of view, no qual uma cena/sequência é mostrada a partir da perspectiva do olhar físico de uma personagem da narrativa (BRANNIGAN, 2005). 
mostrado olhando com perplexidade aquela cena. Closes no rosto de Renato e planos gerais do baile aparecem em montagem alternada. Evidencia-se a oposição entre o conforto e a alegria dos convidados (brancos) e o deslocamento de Renato ao se sentir desamparado por Martha e totalmente excluído daquele ambiente. Desse modo, a integração popular é rapidamente contraposta à hierarquização racial dos espaços de elite.

Essa hierarquização com marcas raciais encontra-se de modo explícito no espaço mais relevante à ação do filme: o casarão de Requião. Ele perpassa a ativação de uma memória traumática cara ao melodrama, ou seja, o recordar da repressão de fundo racial sofrida por Renato e Miro na infância. Também é o lugar que representa o impedimento à realização amorosa de Renato, o que configura um indício do discurso de repulsa à miscigenação, caro à virada entre os séculos XIX e XX. Ainda, é o espaço real e simbólico de afirmação do patriarca branco.

Por esse último motivo, Melo (op. cit., p. 134) chega a afirmar que a casa de Requião seria uma metáfora e uma reminiscência da casa-grande, tal como ao longo dos séculos XVIII e XIX. Concordamos com esta avaliação, na medida em que os personagens referem-se ao casarão com termos que lembram a escravidão (Miro chama Requião de "capitão-do-mato" e sua esposa de "sinhá"). Porém, recordamos que foram detectadas, na sociabilidade presente naqueles espaços, possíveis brechas a uma sexualidade rigidamente concebida pela Igreja, representadas pela posse de suas escravas pelo senhor branco, ao passo que no casarão de Requião ocorre o oposto: o controle da sexualidade da mulher branca pelo impedimento do par inter-racial, em acordo com as ideias sobre raça que aqui chegaram a partir da segunda metade do século XIX. Reconhecemos os espaços da casa-grande e do casarão (urbano) como símbolos de opressão racial, mas em uma lógica de continuidade e não de superposição. Afinal, a própria opressão moderniza-se.

Nesse "novo" espaço, poderíamos apontar a apresentação de uma fronteira étnica (Barth, 2000) que se traduz no acesso desigual e bastante hierarquizado aos diferentes espaços de sociabilidade por brancos e negros. Considerado um recurso acionado nas construções sobre a modernidade, o espaço urbano é segmentado no filme por meio de seu desenvolvimento assimétrico, representado pela oposição entre o tribunal e o casarão (símbolos dos espaços público e privado modernos) e a favela, na qual existe uma maior confusão entre o público e o privado, pela sua ocupação desordenada. A tentativa de integração feita por Renato passaria pela conquista legítima (pela posse de um título de Bacharel em Direito) desses espaços relacionados ao mundo dos brancos, enquanto a negação desse mundo feita por Miro estaria manifestada necessariamente na sua fala desmoralizante dos mesmos espaços.

A este acionamento de uma fronteira étnica, poderíamos acrescentar a cena em que Renato vai à casa de Requião, durante uma festa, para desmascarar Walter Mendes e o ameaça. No entanto, a ameaça inverte-se contra Renato: na conversa no jardim da casa de Requião, além de não surtir efeito, Walter ainda o desafia a entrar na casa e desmascará-lo 
na frente dos convidados: "por que você me diz isso aqui no jardim, escondido como um larápio? Venha pro salão, conte a todos quem eu sou! Chegue no meio da sala e acuse o canalha de ter roubado sua irmãzinha branca" [grifo nosso]. A cena termina com a briga entre os dois e a morte de Walter por um tiro disparado acidentalmente.

Finalmente, valemo-nos da ideia de Melo (op. cit., p. 143), segundo a qual Walter Mendes seria a "máscara branca" de Miro no trânsito por estes espaços, o que seria confirmado pela aliança dos golpistas (depois rompida) e pela circulação apenas de Mendes pelos espaços da casa de Requião e das festas. Assim, as restrições à circulação de Renato e de Miro nos espaços mencionados configurariam um indício da singularidade da hierarquia racial no Brasil: mais diluída entre as classes populares, ela torna-se mais forte à medida que se tenta entrar nos espaços de sociabilidade da classe média e das elites.

Após analisar os modos por meio dos quais Também Somos Irmãos apresenta a circulação das personagens brancas e negras pelos espaços e as formas de hierarquização presentes nesses, passemos a outro ponto: a possibilidade de um romance inter-racial entre Renato e Martha. Moniz Vianna, crítico do jornal Correio da Manhã, assim o descreve:

No meio da trama, há uma jovem, sobrinha do homem que criara os dois negros. Esta jovem considera Renato seu irmão. Sem embargo da cor que os separa irremediavelmente, Renato apaixona-se por ela. É muito discreto e respeitoso, mas sofre terríveis humilhações. A história é conduzida de tal forma que o espectador aguarda, para qualquer momento, o casamento dos dois. Inutilmente (VIANNA, 1949 apud MELO, 2006).

Um ponto da crítica de Vianna merece destaque: o agenciamento do mecanismo trágico na representação do par inter-racial. Em se tratando de relações raciais, a tragédia como ideia não seria algo propriamente novo: os acadêmicos da virada dos séculos XIX e XX - com ênfase no pensamento de Sílvio Romero, bastante influente à época no debate intelectual - elegeram a miscigenação como inimiga na formação do que viria a ser o povo brasileiro no período pós-escravidão (SKIDMORE, 1976). O elemento trágico presente na miscigenação seria o risco de degeneração dos novos indivíduos - pela má conduta, pelo crime, pela indolência. Essa, portanto, mereceria ser combatida pelos intelectuais e pelas autoridades. Como Schwarcz explicitou sobre o trabalho de representação feito pelos intelectuais da época, "a mestiçagem no Brasil não só era descrita como adjetivada, constituindo uma pista para explicar o atraso ou uma possível inviabilidade da nação" (2005, p. 13).

No filme, o par inter-racial é mostrado pelo amor platônico de Renato, que, aos poucos, vai sendo explicitado ao espectador. A partir da simples sugestão, presente no tratamento e nos diálogos entre Renato e Martha, constrói-se uma trajetória dessa revelação: Renato compõe uma música romântica (que será cantada por Hélio, irmão mais novo de Martha, em uma festa na casa de Requião) e, algumas sequências depois, durante uma discussão com Miro, revela a ele suas intenções amorosas com Martha. 
Dois personagens brancos são os principais obstáculos dramáticos à concretização do romance: Requião, que dificulta ao máximo o contato entre os dois, e Walter Mendes, antagonista de Renato na conquista do amor de Martha. A barreira entre Renato e Martha ultrapassa uma dimensão econômica e espacial e passa a ser racializada. E essa racialização opera como um elemento trágico que será compreendido ao final da trama, no diálogo entre Martha e Renato na escadaria da igreja onde costumavam encontrar-se, após este ter matado Mendes, então namorado de Martha.

No processo e após a prisão de Renato, Martha depõe a seu favor, o que foi fundamental para sua libertação. Na última sequência, Renato observa a saída de Martha da igreja, chama-a e diz: "Eu queria Ihe agradecer. Seu depoimento para mim valeu muito. Posso considerar esse seu gesto como um perdão que eu espero de você?". Em um tom muito seco, Martha responde: "Eu só fiz o que parecia de meu dever. Até prefiro que você não me agradeça. Adeus, Renato!". A despedida de Martha é acentuada pelo jogo feito entre dois planos plongée (de Martha) e contre-plongée (de Renato), que acentua a distância entre eles e resume o mecanismo trágico desencadeado na relação amorosa não concretizada.

Entretanto, devemos contrapor que o trágico acionado pelo filme difere da retórica cara aos intelectuais que advogavam contra a miscigenação. Aliás, inverte-a, passando a usar a tragédia para denunciar o preconceito racial: ela não estaria localizada na união em si do casal, mas nas circunstâncias que a impediram, ou seja, o racismo de Requião aliado ao oportunismo de Mendes.

Precisamos sublinhar que a reprodução da família está atrelada, por um mecanismo metonímico, à reprodução dos indivíduos de uma nação (Verdery, 2000) e, simultaneamente, é um elemento caro ao melodrama. Podemos deduzir disso que a concretização do par inter-racial é frustrada por conta da incorporação pelo senso comum do elemento trágico apresentado pelos intelectuais da virada dos séculos XIX e $X X$, sendo este afirmado no filme pela conduta do patriarca Requião e representado pelas barreiras melodramaticamente impostas ao casal.

Essa incorporação ao senso comum passaria, por exemplo, pela construção de um vocabulário de ofensas racistas. Tal fato foi apontado por Melo (op. cit., 146) na cena em que Requião chama Renato de "negrinho ordinário" após este alertá-lo sobre as intenções de Walter Mendes. Essa linguagem racista poderia ser interpretada como a agência de uma hierarquia racial nas interações cotidianas, no sentido de recordá-la aos que participam das interações e operar um esforço de continuidade/manutenção dessa hierarquia.

Mas o filme também mostra o aspecto de disputa em torno da linguagem, através das ações e das palavras de Renato e de Miro. Em uma discussão entre eles, há uma disputa de percepção do mundo social, de suas práticas racistas e das formas de combatê-las. Miro chega bêbado à casa de Renato e os dois iniciam um diálogo no qual Miro começa a recordar a vida no casarão: 
Miro (M): "Você se lembra bem quando a gente era criança? Das maldades do velho Requião com a gente?";

Renato (R): "Pequenas maldades!";

M: "Pra você! Pra mim, não!"

R: "Você era muito rebelde, descontrolado!"

M: "Sim, sim, você sempre dá um jeito e acaba defendendo o velho! Não sei como você aguentou tanto tempo aquele monstro!"

A isso, Miro continua sua fala com desdém e fala de seus planos de vingança contra Requião, mencionando o fato de ter se aliado a Walter Mendes para dar um golpe em seu padrasto. Renato condena a atitude de Miro, o que faz elevar o tom da discussão.
M: "Mas o velho tem nojo da gente. Nós odiamos ele."
R: "Eu nunca odiei ao velho, nem odeio!"
M: "É porque você é de senzala! Você pensa que é um negro livre. Mas não
é! Não tem esse direito. Você não sabe o que é liberdade! Não sente! Você já nasceu escravo! Com alma de escravo! Requião é o teu senhor! Pode te mandar pro tronco que você vai beijar a mão dele!"

Nesse "diálogo que poderia ter lugar em qualquer sociedade do mundo afrodiaspórico" (STAM, 2008, p. 150), o jogo entre as dimensões pedagógica e performativa da narrativa (BHABHA, 2005) é traduzido na disputa a respeito das possibilidades nas trajetórias de homens negros na sociedade e, mais precisamente, na oposição melodramática entre integração e vingança. Ao passado de dor e de trauma, Renato contrasta a via de ascensão social pelo estudo, ao passo que Miro rompe (ao menos, neste momento) com a perspectiva legalista e de mérito de seu irmão, optando pela marginalidade como uma forma de se contrapor ao mundo dos brancos e, para isso, vale-se da "máscara branca" de Mendes. Ao conflito entre as linguagens adotadas por Renato e Miro superpõem-se essas duas diferentes visões sobre a integração do negro na sociedade brasileira pós-escravidão.

Todavia, há uma conformidade entre as ações de Renato e de Miro: ambas são percebidas como construções intelectuais ou, usando uma nomenclatura weberiana, "tipos ideais" de ação social. Através das trajetórias dessas personagens, podemos compreender o campo possível das respostas dos intelectuais à temática do preconceito racial. E mais: é possível perceber a postura dos intelectuais diante do povo e de seu conteúdo étnico. Vejamos o diálogo em que Miro, após essa briga com Renato, fica bêbado e confronta uma "baiana"3 que se encontra na calçada do bar do qual acabara de sair:

Miro: "Olá, baiana! Como vai? Você acredita nessa história de preto que tem alma branca?"

Baiana: "Qual nada, meu filho! As almas são tudo da mesma cor."

Miro: "Pois sim! A minha alma é mais preta do que essa mão que você tá vendo!"

3 Vendedora de artigos caros às religiões afro-brasileiras, assim chamada no filme. 
Baiana: "Olha o castigo!"

Miro: "Preto com alma branca... Preto com alma branca é fantasma!"

Essa interação com a baiana é um forte indício da visão dos intelectuais ligados ao cinema na época, que apresentaram imagens de um povo desprovido de capacidade intelectual. De acordo com ela, o povo não teria legitimidade para falar de si; para isso, seria necessário que outros o fizessem. Miro e Renato são, portanto, focalizados pela narrativa como representantes intelectuais desse povo. Para completar, ainda há uma desautorização do conteúdo étnico e religioso desse povo - aqui expressado pelo rebaixamento de uma personagem ligada às religiões afro-brasileiras.

A disputa por significar (BHABHA, 2005) entre Renato e Miro encontra-se no duplo reconhecimento de que suas trajetórias seriam "tipos ideais" na ação dos homens negros em busca de ascensão social e de que são instâncias autorizadas para isso. Chegamos à capacidade projetiva das ações dessas personagens, ou seja, ao reconhecimento de que há uma subordinação dessas ações a um projeto, entendido como o cálculo entre a disposição individual e os recursos a ela acessíveis. Velho (1994), apropriando-se de Simmel, reconhece no projeto uma característica fundamental da modernidade, uma vez que a desestabilização de uma velha ordem concedeu aos sujeitos uma margem de escolha maior. Isso não significa postular que a modernidade "libertou" de vez os sujeitos, mas apenas que um espaço para o cálculo racional das ações fora criado e, com ele, ampliou-se a capacidade individual de projetar condutas em busca de determinados resultados.

Podemos inferir que tanto Renato quanto Miro valem-se desse cálculo racional em busca de resultados: aceitação e, com ela, ascensão social (para Renato) ou posse da riqueza dos brancos (para Miro). Ao mesmo tempo, por serem construídos como representantes intelectuais, incorporam dois tipos de projetos coletivos possíveis: a integração social (Renato) ou a insubordinação racialmente motivada (Miro).

Contudo, há o cruzamento dessa noção de projeto com outra muito cara ao melodrama: a de destino. Nas palavras de Melo: "o filme coloca em primeiro plano a questão racial, determinando o destino dos protagonistas (Miro e Renato), sem deixar de remarcar o sacrifício e, portanto, a moral cristã" (op. cit., p. 136, grifo do autor). Neste ponto, poderíamos destacar que as categorias raciais operariam como um redutor na capacidade de formular e executar ações ligadas aos projetos dos personagens. Para salvar o irmão, Miro precisa redimir-se perante o mundo dos brancos e pedir a Martha para que deponha a favor de Renato. Por sua vez, Renato também é auxiliado por Martha (cujo depoimento o livra da cadeia) e por Hélio, que conduz a negociação entre Martha e Miro e convence a primeira da importância de seu depoimento no caso. E, como fica claro ao final, junto com esse auxílio, vem a recusa amorosa, a dose de sacrifício de Renato.

No destino melodramaticamente encenado das personagens, no momento em que tem seu depoimento colhido na delegacia e percebe que o autor do crime é Renato, 
Miro resolve confessar a autoria do crime para salvar o irmão. Neste ponto, fica patente o apelo a uma solidariedade de cunho racial. No diálogo que travam na cela da cadeia em que Miro está, ficam claros a redenção deste e o investimento no projeto de integração, tal como encampado por Renato. Miro tenta convencer o irmão de que seria melhor se ele assumisse a culpa em seu lugar e, diante da resistência, diz: "Renato, você é a única coisa decente que eu tenho na vida!". Lembrando que essa fala se dá em um close no qual o rosto de Miro é focalizado com lágrimas, pode-se inferir que essa composição concede um ar de confissão ao momento.

E o investimento de Miro nessa solidariedade racial não se encerra aí: supera suas limitações para com o casarão e vai até lá em busca de Martha. No jardim, revela a Hélio que sente saudades da infância, mas reluta em entrar no casarão. E, ainda, revela um traço de submissão: ao ver Hélio abrir a porta da sala, retruca: "Você não acha melhor entrar pela porta da cozinha?". Na chegada de Martha à sala, a submissão completa-se: um plano americano que vai se fechando pelo movimento da câmera até um plano médio de Miro é contraposto a um plano geral que mostra a descida de Martha pela escadaria do casarão. Em seguida, não olha diretamente para Martha e dialoga com ela cabisbaixo.

Nessas sequências, evidencia-se a negociação de Miro com os brancos e, em paralelo, o reconhecimento do projeto de Renato: a integração. Porém, o faz a partir de um sentimento de solidariedade que transcende o vínculo de sangue. Sendo a integração um projeto de Renato, que, metonimicamente, refere-se aos homens negros, há um agenciamento por parte de Miro dessa solidariedade racial na busca por aquela. Assim, a reconciliação e o engajamento na busca pela liberdade do irmão remetem à capacidade deste em sustentar este projeto de integração - pelas vias finalmente reconhecidas como legítimas por Miro (diploma de bacharel, comportamento contido, luta nos espaços do branco). Aliás, isso se coaduna com o pensamento propagado do movimento negro da época, que pregava a integração do homem negro à nação brasileira (GUIMARÃES, 2002; NASCIMENTO, 2003).

Melo (op. cit., p. 159) elenca, como um dos motivos da pouca recepção do filme e do posterior apagamento em torno dele pela intelectualidade ligada ao cinema, uma ideologia nacionalista sustentada por esta (e.g. Paulo Emilio Sales Gomes, Glauber Rocha e até mesmo Alex Viany, que à época escreveu uma crítica favorável ao filme). É possível ampliar esse argumento, afirmando que o habitus do campo cinematográfico que estava sendo formado no final dos anos 1940 e início dos anos 1950 incorporou o ideal de integração/democracia racial. Isso significa postular que, para além da crítica e da intelectualidade, a visão de povo que iria embasar as futuras produções cinematográficas e as práticas de seus realizadores (diretores, produtores, roteiristas), de seus financiadores (bancos e o próprio Estado) e de seus censores - que, em determinados momentos, assumiram um papel importante no jogo político que envolve a produção, a distribuição e exibição dos filmes - seria encampada no sentido de reforçar uma heterogeneidade na composição étnica nacional, porém que esta conviveria sem grandes conflitos. 
Em uma entrevista veiculada no momento da exibição do filme nos cinemas cariocas ${ }^{4}$, José Carlos Burle descreveu a experiência prévia ao filme como uma ideia surgida casualmente, durante uma caminhada pelo bairro carioca de São Cristóvão:

Depois de muito andarmos, perdemo-nos num labirinto de ruas estreitas. (...) Casebres de todos os lados. Gente de cor indo e vindo continuamente por aqueles caminhos sinuosos. Mulheres de lata d'água à cabeça. Crianças correndo daqui para ali na algazarra própria da idade. Homens de físico reforçado gingando o corpo no andar típico dos malandros de classe. (...) Continuamos a andar em silêncio quando Alinor, que parecia ter lido meus pensamentos, exclamou de repente:

- Já tenho a história em que você está pensando.

Sim, era verdade. Alinor havia me mostrado, há tempos, o esboço de um argumento que principiara a escrever. Lembrei-me do título:

Gente de Cor. Não... não servia... Não era um bom título. Poderia ser mal interpretado. Era preciso escolher algo mais humano, que tocasse o coração do povo.

(...)

E o título surgiu numa explosão: Também Somos Irmãos... Sim! Narraríamos as histórias daqueles nossos irmãos de cor, as suas esperanças, os seus sofrimentos, os seus erros.

Alinor expôs-me rapidamente o seu plano.

Colocaríamos nessa favela dois irmãos. Um seguiria o caminho do crime. Seria o famoso "Moleque Miro". Outro procuraria dignificar a raça conquistando um diploma na Faculdade de Direito. Um negro de navalha sempre empalmada com um irmão "doutor" que o defenderia no júri das trapalhadas em que se metesse. Para movimentar melhor a história, os dois irmãos estavam vinculados a uma família rica.

Nessa ocasião, restou claro o acionamento de uma imaginação melodramática (Brooks, 1995) por parte do diretor, na medida em que este se deparou com um "mundo estranho, de gente humilde, mas cheia de colorido e pitoresco" e sentiu a necessidade de narrar "os dramas daquelas vidas tão cheias de contrastes", além de apresentar dois irmãos como polos antagônicos no filme.

É preciso evidenciar que o antagonismo referia-se à personalidade e à trajetória escolhida, mas não ao desenrolar da trama, uma vez que, embora com resistências, o irmão advogado auxiliou o irmão envolvido com crimes. Além disso, remeteu-se à construção narrativa sobre a inserção do negro na sociedade da época: ou ela ocorre por meio da aceitação das regras sociais e do espaço do branco ou pela contestação radical das mesmas, sendo a própria oposição entre essas possibilidades uma fonte para a imaginação melodramática dos realizadores cinematográficos.

4 In:__. Como surgiu a ideia de Também Somos Irmãos. In: O Jornal: Rio de Janeiro, 11 set 1949, p. 10 (da Revista em anexo ao jornal). Pelo fato de haver, ao lado desta coluna, outra reportagem de Pedro Lima sobre a chegada de Alberto Cavalcanti ao Rio de Janeiro e de que não há a assinatura de nenhum outro colunista na parte de cinema do Jornal, suspeitamos que a primeira também seja de sua autoria. 
A ideia de apadrinhamento de dois negros por uma família rica branca, que também foi apresentada na entrevista como plot do filme concebido, inseriu-se nesta imaginação racial proposta pelo filme. Afinal, como dissociá-la da estrutura de uma sociedade saída da escravidão há menos de 60 anos e na qual a figura do "coronel", do patriarca, ainda permeava as relações no cotidiano e na política?

Ainda na entrevista, a ideia de ambientar o filme em uma favela pode ser lida como o entrecruzamento dos lugares de raça e de classe nas quais as práticas desses intelectuais localizam os negros. Ao ligar negros e pobreza e, por oposição melodramática, brancos e riqueza, Burle sinalizou que as barreiras à inserção do negro operam tanto no plano simbólico (discriminação racial) quanto no econômico (restrição ao acesso a bens). O primeiro título do argumento - Gente de Cor - e o motivo alegado para a mudança posterior ("Não era um bom título. Poderia ser mal interpretado") corroboram para a encenação desta barreira e para o incômodo possivelmente gerado no espectador - tal como imaginado pelo diretor - ao abordar de forma tão explícita o tema do preconceito racial. A justificativa sobre o título final do filme explicita o engajamento afetivo proposto ao espectador em torno da questão racial, uma vez que Também Somos Irmãos propor-se-ia a apresentar "as histórias daqueles nossos irmãos de cor, as suas esperanças, os seus sofrimentos, os seus erros".

\section{Considerações Finais}

Diante do exposto, a construção de uma fronteira étnica através dos espaços de sociabilidade das personagens interfere na trajetória do par inter-racial e nas possibilidades de sua união (não concretizada). Somando-se a isso a linguagem racista e a disputa na nomeação do mundo social e na formulação de projetos por Renato e Miro, podemos concluir que o filme questiona, por um lado, o ideal de democracia racial, tal como formulado pelos acadêmicos em voga nos vinte anos anteriores, que ajudaram a construí-lo, em sintonia com a percepção de Stam de que o filme é "assustador pela maneira corajosa com que trata de um tema-tabu - o racismo e a discriminação" (2008, p. 149).

Entretanto, pelo fato de desmerecer o conteúdo étnico do povo retratado, de projetar no intelectual a capacidade de transformação das relações sociais e de mostrar uma solidariedade racial que se redime perante o mundo dos brancos por um projeto de integração, Também Somos Irmãos não significa uma ruptura completa com a democracia racial. Ao denunciar o preconceito racial, o filme o faz por meio de uma narrativa que explora as oposições entre negros e brancos, mas de forma a mostrar possíveis redes de solidariedade e atribuindo a alguns personagens (Renato, Martha, Hélio e, no final, Miro) a comunicação entre eles.

Podemos concluir que a abordagem de situações de preconceito racial não implica necessariamente um questionamento ao ideal de democracia racial. Apesar de haver 
um choque a esta nas falas de Miro e nas situações apresentadas cenicamente, a narrativa de Também Somos Irmãos legitima, ao seu final, um apelo à via da integração das massas negras ao capitalismo "à brasileira".

É possível destacar que o principal aspecto precursor do filme reside na encenação de uma solidariedade racialmente motivada, em sintonia com o movimento negro da época. Também merece destaque o reconhecimento de personagens negros como intelectualmente capazes de projetar suas condutas de modo a obter ganhos sociais.

Por fim, verificamos a encenação de um ideal de branqueamento que perdurou mesmo após a disseminação das ideias de Gilberto Freyre e que, por exemplo, vedava a presença de negros em certos espaços sociais e impedia a concretização de uma relação afetiva entre uma mulher branca e um homem negro. Desse modo, Também Somos Irmãos retira do branco sua neutralidade (DYER, 1997), explicitando-a como categoria discursiva, de leitura do mundo social e localizando-a entre o racismo (Requião), a hipocrisia das convenções sociais (Mendes) e o objeto do desejo trágico (Martha).

Pedro Vinicius Asterito Lapera é doutor em Comunicação pelo PPGCOM-UFF e pesquisador da Fundação Biblioteca Nacional (FBN-MinC).

plapera@gmail.com

\section{Referências}

BARTH, F. O guru, o iniciador e outras variações antropológicas. Rio de Janeiro: Contracapa, 2000.

BHABHA, H. O Local da cultura. Belo Horizonte: Ed. UFMG, 2005.

BOURDIEU, P. A Economia das trocas simbólicas. São Paulo: Perspectiva, 2005.

BRANNIGAN, E. O ponto de vista. In: RAMOS, Fernão (org). Teoria Contemporânea do Cinema volume II. São Paulo, SENAC, 2005.

BROOKS, P. The Melodramatic imagination: Balzac, Henry James, melodrama, and the mode of excess. New Haven: Yale University Press, 1995.

DYER, R. White: essays on race and culture. New York: Routledge, 1997.

GUIMARÃES, A. S. Classes, raças e democracia. São Paulo: Ed. 34, 2002.

MELO, L. A. R. Argumento e roteiro: o escritor de cinema Alinor Azevedo. Dissertação defendida junto ao PPGCOM-UFF. Niterói, 2006. Orientadora: Profa. Dra. Hilda Machado.

NASCIMENTO, A. Quilombo: vida, problemas e aspirações do negro. São Paulo: FUSP/34, 2003.

SCHWARCZ, L. M. O Espetáculo das raças: cientistas, instituições e questão racial no Brasil (18701930). São Paulo: Cia. das Letras, 2005. 
SINGER, B. Melodrama and modernity: early sensational cinema and its contexts. New York: Columbia University Press, 2001.

SKIDMORE, T. Preto no branco: raça e nacionalidade no pensamento brasileiro. Rio de Janeiro: Paz e Terra, 1976.

STAM, R. Multiculturalismo tropical: uma história comparativa da raça na cultura e no cinema brasileiros. São Paulo: Edusp, 2008.

SZONDI, P. Ensaio sobre o trágico. Rio de Janeiro: Jorge Zahar, 2004.

VELHO, G. Projeto e metamorfose: antropologia das sociedades complexas. Rio de Janeiro: Jorge Zahar, 1994.

VERDERY, C. Para onde vão a "nação" e o "nacionalismo"? In: BALAKRISHNAN, G. (org.). Um Mapa da questão nacional. Rio de Janeiro: Contraponto, 2000, p. 239-247.

Artigo recebido em janeiro e aprovado em agosto de 2015. 